\title{
Hip disease in juvenile rheumatoid arthritis
}

\author{
I. C. ISDALE \\ From the Queen Elizabeth Hospital, Rotorua, New Zealand
}

Rheumatoid arthritis in children was first described over a century ago, and ever since, particularly after the publication of Still's classical paper, the features which tend to distinguish the childhood presentation from that seen in the adult have been emphasized. These differences are now well accepted, but in children as in adults, the disease has its major impact on the joints of the locomotor system (Sairanen, 1958). In adults the peripheral joints are usually the most important areas involved from the time of onset; in children the larger joints more often bear the brunt of the disease, particularly the knees, ankles, and wrists, and, less commonly, the hips (Edström, 1967). At any age involvement of the hip is important as it may lead to serious locomotor difficulties. Despite its importance as a cause of disability, hip disease in juvenile arthritic patients has been studied much less than many of the other manifestations of the disease.

\section{Material and methods}

In the decade 1958-1968, 85 children all fulfilling the criteria (Ansell and Bywaters, 1959) for the diagnosis of juvenile rheumatoid arthritis (JRA) were admitted to the Queen Elizabeth Hospital, Rotorua, and these children have been followed for a minimum period of 3 years. Most of these patients had hip $x$ rays and all had followup assessments. The type of disease onset, the presence or absence of hip disease, the changes in functional status (Ansell, 1969) and the clinical and serological findings have been analysed. In those with clinical involvement of the hip, the radiographic changes have been analysed with particular emphasis on the presence or absence of growth defect.

The classification used in this Unit for characterizing the onset of the disease is adapted from that of Calabro and Marchesano (1967). The patients are divided into three groups: those who have an acute onset with widespread joint involvement, marked fever, lymphadenopathy, splenomegaly, and other extra-articular manifestation ('acute type'); those who have involvement in one, two, or three joints and have had synovial biopsy ('oligoarticular type'); and those with chronic low-grade peripheral polyarthropathy of a pattern much like that seen in adult cases ('chronic type'). Rheumatoid factor tests were performed by the sheep cell agglutination method of Whillans and Fischman (1958). In two cases this test was not performed, but in the great majority the test was performed on many occasions. Only those cases which were negative on all occasions were classed as sero-negative.

\section{Results}

Of the 85 cases, 32 had clinical and radiological involvement of the hips during the period of observation. One other child is known to have growth defects but is without clinical hip disease. The breakdown by age shows that among the very young children hip involvement is the rule (Table I). The overall incidence of 38 per cent. in the series forms a striking contrast to the incidence of up to 10 per cent. among chronic adult hospitalized cases. The incidence of hip disease among the 4 to 9 -year age group and the 10 to 15 -year age group was comparable (30 per cent.), but among the children with onset before the 4th birthday, twelve out of nineteen showed hip involvement. The incidence in boys and girls was comparable and there was no signi-c ficant difference in sero-positivity between those with hip disease and those without (Table II). Of the whole group, 72 per cent. were persistently seronegative.

Table I Hip disease in 85 cases of JRA, by age at onset

\begin{tabular}{|c|c|c|c|c|}
\hline \multirow[t]{2}{*}{ No. of cases } & \multicolumn{3}{|c|}{ Age at onset (yrs) } & \multirow[t]{2}{*}{ Total cases } \\
\hline & $0-3$ & 4-9 & $10-15$ & \\
\hline Total & 19 & 30 & 36 & 85 \\
\hline $\begin{array}{l}\text { Hip disease No. } \\
\text { Per cent. }\end{array}$ & $\begin{array}{l}12 \\
63\end{array}$ & $\begin{array}{r}9 \\
30\end{array}$ & $\begin{array}{l}11 \\
30\end{array}$ & $\begin{array}{l}32 \\
38\end{array}$ \\
\hline
\end{tabular}

Table II Sex and RA factor test in 85 cases of JRA

\begin{tabular}{|c|c|c|c|c|}
\hline \multirow[t]{2}{*}{ No. of cases } & \multicolumn{2}{|l|}{ Sex } & \multicolumn{2}{|c|}{$R F$ inhibition test } \\
\hline & Male & Female & Positive & Negative \\
\hline $\begin{array}{l}\text { With hip disease } \\
\text { With normal hips }\end{array}$ & $\begin{array}{r}7 \\
15\end{array}$ & $\begin{array}{l}25 \\
38\end{array}$ & $\begin{array}{l}10 \\
12\end{array}$ & $\begin{array}{l}21 \\
40\end{array}$ \\
\hline Total & $\begin{array}{l}22 \\
x^{2}= \\
0.42\end{array}$ & $\begin{array}{l}63 \\
\text { NS }\end{array}$ & $\begin{array}{l}22 \\
\chi^{2}= \\
0.96\end{array}$ & $\begin{array}{l}\text { NS } \\
\text { NS }\end{array}$ \\
\hline
\end{tabular}

NS = not significant. 
Table III shows the breakdown by age of types of onset and the incidence of hip disease in each group. Approximately half the children presented with chronic generalised disease (41 out of 85 ), about a quarter (21 out of 85) with oligo-articular disease, and the remaining 23 with acute disease. In the younger age groups the acute type, and in the older age groups the generalized chronic type of onset was more usual. Regardless of age, those cases with an acute onset showed a statistically higher incidence of hip disease in the subsequent course (17 out of 23) than those with oligo-articular or chronic onset (Table III).

The duration of disease before the onset of hip symptoms and signs was investigated, and it was noted that in most cases hip involvement occurred comparatively early in the disease, in the first 7 years. In those few cases in which it occurred later it was almost invariably associated with an acute exacerbation (Table IV). Most of the children who have not shown hip disease, have been followed for more than 9 years and, except where there have been growth defects which have not yet caused signs and symptoms, it is thought unlikely they will develop hip disease in the future.

Table IV Time from onset to hip involvement

\begin{tabular}{|c|c|c|c|c|}
\hline \multirow{2}{*}{$\begin{array}{l}\text { Duration from } \\
\text { onset to hip } \\
\text { disease (yrs) }\end{array}$} & \multicolumn{3}{|c|}{ Age at onset (yrs) } & \multirow[t]{2}{*}{ Total cases } \\
\hline & $0-3$ & $4-9$ & $10-15$ & \\
\hline $\begin{array}{l}\text { Under } 3 \\
3-4 \\
5-7 \\
8-9 \\
10+\end{array}$ & $\begin{array}{r}2 \\
2 \\
4 \\
4 \\
-\end{array}$ & $\begin{array}{l}2 \\
3 \\
2 \\
2\end{array}$ & $\begin{array}{r}2 \\
4 \\
5 \\
- \\
\end{array}$ & $\begin{array}{r}6 \\
9 \\
11 \\
4 \\
2\end{array}$ \\
\hline Total & 12 & 9 & 11 & 32 \\
\hline
\end{tabular}

Three patients developed hip flexion contractures, not as a result of hip disease but secondary to knee joint disease. Each of these patients has been followed for more than 3 years since the correction of the knee flexion (which was achieved by soft tissue surgery to the hamstring muscles), and in each case the hips remain symptom free with normal movement and $x$-ray appearances.

The follow-up status of these children demonstrates the importance of hip disease in restricting functional ability. At the 9-year level, only eight of 26 patients with hip disease are in the top two functional grades as compared with 26 of 28 patients without hip disease. The hip complaint is the major cause of restricted function in nearly every case (Table V).

Table V 9-year follow-up status (54 patients)

\begin{tabular}{|c|c|c|c|c|c|c|}
\hline Patients & $\begin{array}{l}\text { Func } \\
5\end{array}$ & $\begin{array}{l}\text { tiona } \\
4\end{array}$ & status & 2 & 1 & Total cases \\
\hline $\begin{array}{l}\text { Hip involvement } \\
\text { Normal hips }\end{array}$ & $\begin{array}{r}1 \\
16\end{array}$ & $\begin{array}{r}7 \\
10\end{array}$ & $\begin{array}{r}13 \\
2\end{array}$ & 5 & $\overline{-}$ & $\begin{array}{l}26 \\
28\end{array}$ \\
\hline
\end{tabular}

The chief radiological findings in the affected patients are shown in Table VI. All had bilateral changes with early osteoporosis but little bone destruction. Loss of joint space was a late feature except in some of the older children and osteophytosis was minimal. Nearly all the twelve cases in which the disease started before the 4th birthday showed growth defects in the acetabulum and/or

Table VI Radiological changes in affected hips

\begin{tabular}{|c|c|c|c|c|}
\hline \multirow{2}{*}{$\begin{array}{l}\text { Radiological } \\
\text { changes }\end{array}$} & \multicolumn{3}{|c|}{ Age at onset (yrs) } & \multirow{2}{*}{$\begin{array}{l}\text { Total } \\
\text { cases }\end{array}$} \\
\hline & $0-3$ & 4-9 & $10-15$ & \\
\hline $\begin{array}{l}\text { Definite growth } \\
\text { defects } \\
\text { Protrusio acetabuli } \\
\text { Bony ankylosis } \\
\text { Luxation } \\
\text { Coxa valga }\end{array}$ & $\begin{array}{r}10 \\
1 \\
2 \\
5 \\
6\end{array}$ & $\begin{array}{l}3 \\
2 \\
0 \\
2 \\
3\end{array}$ & $\begin{array}{l}0 \\
7 \\
0 \\
0 \\
0\end{array}$ & $\begin{array}{r}13 \\
10 \\
2 \\
7 \\
9\end{array}$ \\
\hline Total cases & 12 & 9 & 11 & 32 \\
\hline
\end{tabular}

Table III Age at onset and type of onset

\begin{tabular}{|c|c|c|c|c|c|c|c|c|}
\hline \multirow[t]{3}{*}{ Age at onset (yrs) } & \multicolumn{8}{|c|}{ Type of onset } \\
\hline & \multicolumn{2}{|l|}{ Acute } & \multicolumn{2}{|c|}{ Oligo-articular } & \multicolumn{2}{|l|}{ Chronic } & \multicolumn{2}{|l|}{ Total cases } \\
\hline & Hip cases & All cases & Hip cases & All cases & Hip cases & All cases & Hip cases & All cases \\
\hline $\begin{array}{l}0-3 \\
4-9 \\
10-15\end{array}$ & $\begin{array}{l}7 \\
5 \\
5\end{array}$ & $\begin{array}{l}8 \\
7 \\
8\end{array}$ & $\begin{array}{l}3 \\
0 \\
2\end{array}$ & $\begin{array}{l}5 \\
7 \\
9\end{array}$ & $\begin{array}{l}2 \\
4 \\
4\end{array}$ & $\begin{array}{r}6 \\
16 \\
19\end{array}$ & $\begin{array}{r}12 \\
9 \\
11\end{array}$ & $\begin{array}{l}19 \\
30 \\
36\end{array}$ \\
\hline Total & 17 & 23 & 5 & 21 & 10 & 41 & 32 & 85 \\
\hline
\end{tabular}


femoral head area. These included early closure of the pelvic epiphyses, undergrowth of the femoral head and neck, and irregular and early closure of the femoral head epiphysis (Fig. 1). In two cases these changes were very striking, in eight they were moderate, and in one there was dubious change. Only three of the nine patients with hip disease starting between the ages of 4 and 10 years showed definite growth defects; two others showed some irregularity of the femoral head which may have been due to bone erosion. In three of these, as in the very young patients, persistence of coxa valga was seen. Of those with onset after the 10th birthday, two showed irregularity of the femoral head, but none showed definite growth defects.

Protrusio acetabuli, the common radiological abnormality in adult rheumatoid coxitis, was seen in only one of the children in whom the disease started before the 4th birthday, and two of those with onset between the ages of 4 and 10, but in no less than seven of the nine in the oldest age group (four showing this to "marked degree). In a few cases cartilage destruction and protrusio acetabuli developed slowly over a considerable time but in most patients the changes developed rapidly, in as short a period as 4 months, from normal $x$-ray appearances to gross loss of joint space and early protrusio acetabuli.

Subluxation was seen in seven cases, five being in the youngest age group where growth defects and persistence of coxa valga probably had a part to play (Fig. 2). Bony ankylosis of the joint was seen in only two patients, both of whom had protracted periods of immobilization during the period of active coxitis.

\section{Discussion}

The 38 per cent. incidence of hip disease in cases of JRA in this study is comparable with that found by Sairanen (1958) at Heinola, but much less than the 63.5 per cent. reported by Jacqueline, Boujot, and Canet (1961) in their detailed study from Aix-lesBains. This difference is probably due to differences in the admission policy of these units, for patients with hip disease form a disabled group who are more likely to be hospitalized than other patients with JRA. Of greater importance is the demonstration that it is the youngest group of patients, and those with acute onset, which appear to be most

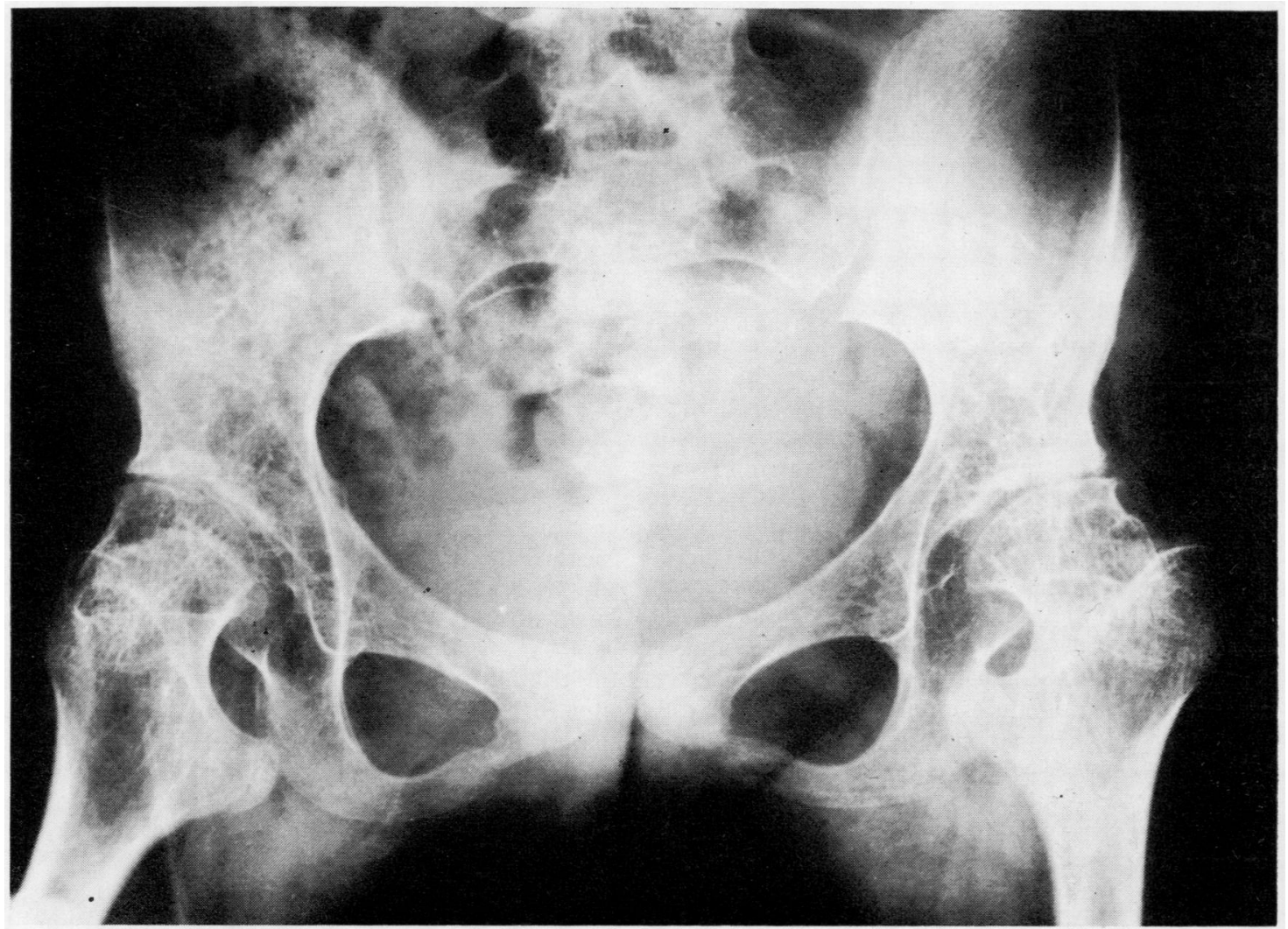

FIG. 1 Radiographs of hips of a child aged 10 years, who had acute onset of Still's disease at the age of 18 months, with early hip involvement. Closure of epiphyses with marked growth defects. 


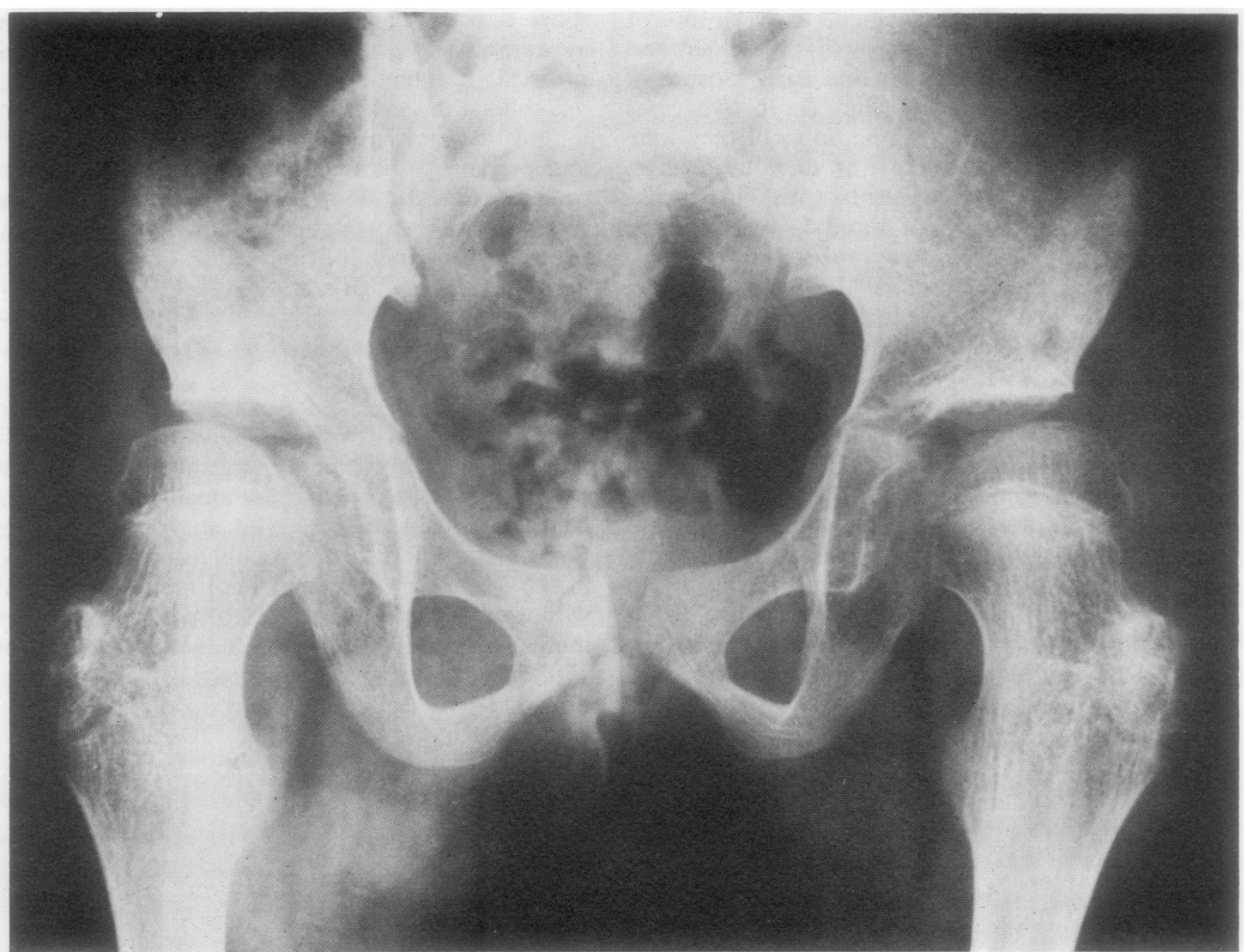

FIG. 2 Radiographs of hips of a child aged 10 years, who had acute onset of Still's disease at the age of 3 years with hip involvement at the start. Marked coxa valga with luxation.

liable to develop hip disease. Regardless of the age at onset, patients with JRA tend to develop hip disease early, occasionally at the onset, more frequently 3 to 6 years after the onset (Sairanen, 1958; Jacqueline and others, 1961). The few patients in this series who developed hip symptoms and signs more than 7 years after the onset of JRA did so when there was a general exacerbation of the disease.

The most characteristic features of the radiological changes, particularly in the younger cases, which distinguished JRA from adult rheumatoid coxitis were growth defects. There are two important mechanisms for the development of growth defects in these young patients.

The first follows acceleration of fusion of the epiphysis, related to the intensity of the inflammatory process. In severe cases this may be marked (Ansell and Bywaters, 1956). Such premature fusion can be faulty, particularly the fusion of the cephalic epiphysis of the femur. Cartilage islands may persist and growth may continue in one part of the epiphysis longer than another, giving an irregular closure. This early arrest of growth may be seen not only in the femur but also in the bones of the acetabulum with underdevelopment and obliquity of the upper and outer rim of the acetabulum. The underdevelopment of the inner part of the head with the obliquity of the outer part of the acetabulum gives a picture very like that seen in congenital acetabular dysplasia (Jacqueline and others, 1961).

The second mechanism is the modification of the normal maturation of the bones round the hip joint during the early years of childhood, following the acquisition of the upright stature and the use of the hip in locomotion. The greater part of this remodelling takes place in the first 4 years of life, but further change continues until at least the age of 8 ; during these years the femoral neck moves from a coxa valga position with an angle of inclination of the neck of approximately $145^{\circ}$ and an angle antiversion of $26^{\circ}$, to $125^{\circ}$ and $8^{\circ}$ respectively in the normal adult.

In this study as in others (Jacqueline and others, 1961; Sairanen, 1958), growth defects were found to occur only in the youngest children, thirteen of the 21 with onset below the age of 10 years showing 


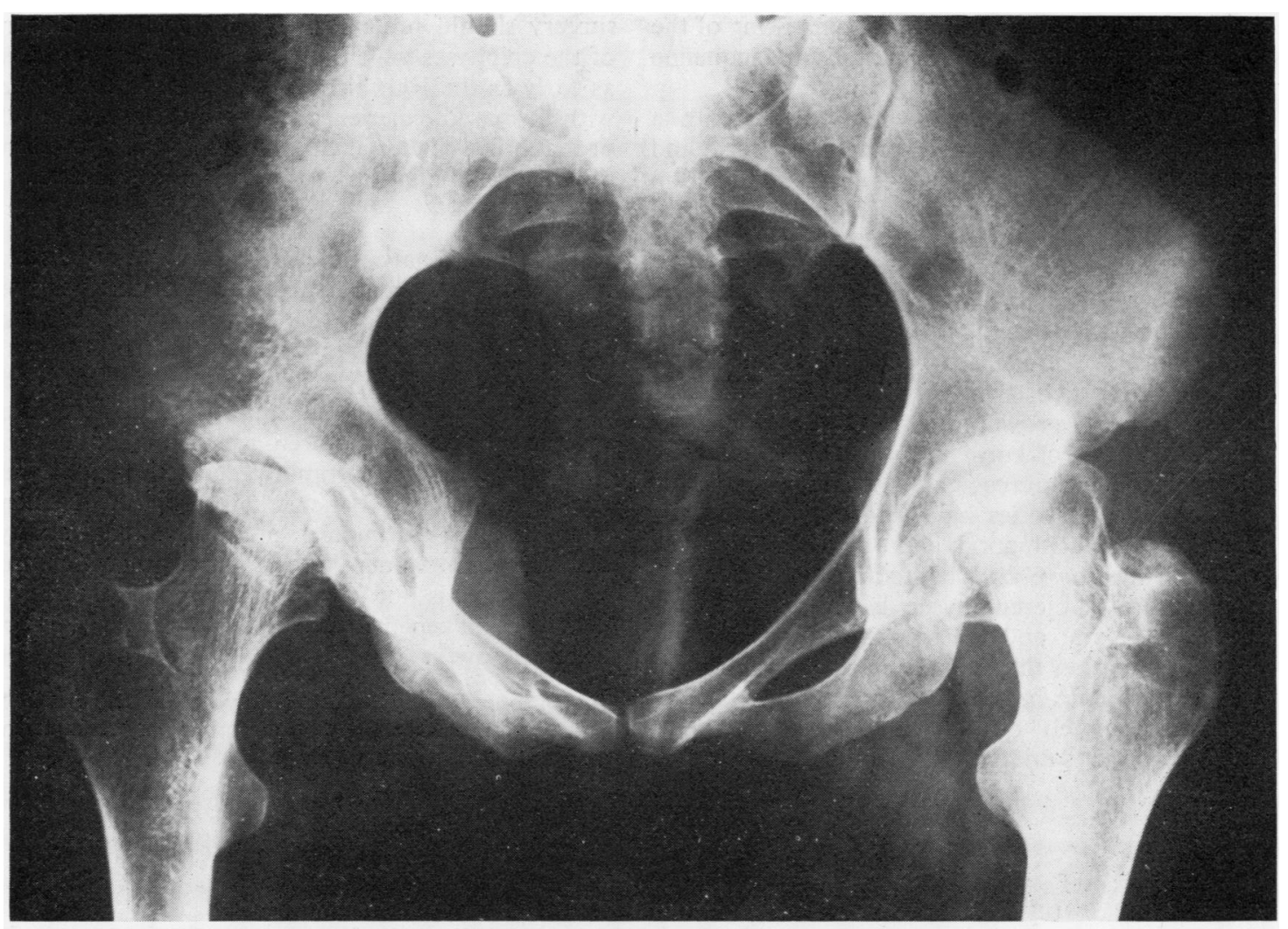

FIG. 3 Radiographs of hips of a patient aged 19 years, whohadonset of oligoarthritis at the age of 7 years. Growth defects of hips never clinically affected.

epiphyseal changes and nine of the 21 showing persistence of coxa valga. The appearances of the hips in these cases must be differentiated from that seen in congenital acetabular dysplasia in some cases, and in epiphyseal dysplasia in others. All patients in this study had walked normally and at a normal age before the onset of hip disease. In a few of the children, films taken before the development of hip disease made it easy to exclude acetabular dysplasia, but not all patients had such films. The absence of dyplastic change in other epiphyses makes epiphyseal dysplasia as the cause of the changes observed unlikely. Occasionally growth defects occur in patients not clinically affected by hip disease; such defects usually lead to joint incongruity and secondary degenerative changes. One child in this series is known to have asymptomatic growth defects which presumably followed subclinical hip involvement (Fig. 3).

In his study of the clinicoradiological aspects of JRA, Sairanen (1958) placed considerable emphasis on subluxation occurring in cases with hip disease. This he found principally among patients with onset below the age of 6 years, and, as this frequently occurred soon after the hips became involved, he felt that many cases had distension luxation due to synovial hypertrophy and effusion in the joint. The other major cause of luxation follows the development of growth defects. In the present series luxation was seen less frequently than in either the series of Sairanan or that of Jacqueline and others (1961), but characteristically it involved the youngest group of children. Ankylosis too was less frequent in this series, possibly because of the avoidance of long periods of immobilization. The two cases that showed this ankylosis were, in fact, treated with a long period of rest in bed during the active stage of coxitis.

The radiological appearances of the older children show features common in adult rheumatoid arthritic patients. Protrusio acetabuli was occasionally seen in the younger children but was much more common in the older children. The one distinguishing feature in these teenage children was the early onset of hip disease after the onset of juvenile rheumatoid arthritis and the rapid development of severe disease with early cartilage destruction as evidenced by a loss of joint space. This contrasts markedly with the 
coxitis of young children, in whom narrowing of the acetabular space is a late manifestation (Jacqueline and others, 1961).

The patients in this series were treated with a conservative programme of graduated exercise and rest with avoidance of long periods of immobilization and the use of aspirin and other analgesics. Oral corticosteroids were used in about a quarter of the patients, but gold was given in only a few cases. Effective measures to control local disease and to prevent growth defects are not yet known. Drug therapy has not proved to be of great help; local therapy with corticosteroids or synovectomy (Duthie, 1965) is not of proven worth. In the late stages surgery may be of considerable value, though no one operative technique is agreed as optimal. Three children in these series have had cup arthroplasty performed, two with good, and one with indifferent, results. Three have had bilateral hip replacement after closure of the epiphyses, between the ages of 16 and 23 years; and the results in all three have been excellent, so that a large measure of function and independence has been restored. Other patients remain moderately or severely disabled, but have not yet been subjected to surgery. Restorative surgery should preferably be left until the closure of the epiphyses which, in some cases, has occurred as early as the 10th birthday (Fig. 1). In the future, with increased experience, surgical intervention will probably be undertaken earlier, leading to more effective rehabilitation of these disabled children.

\section{Summary}

Retrospective analysis of the incidence of hip disease in 85 cases of juvenile rheumatoid arthritis is presented. A high incidence of hip involvement, particularly in the younger patients and in those with acute onset of polyarticular disease, has been shown. Growth defects and hip luxation were common in the younger children, while in older children the changes, at times rapidly developing, followed the adult pattern. Patients with hip involvement showed a marked impairment of functional ability. The long-term value of surgery and other measures in such cases is not yet clear, but some have shown considerable benefit from hip surgery after cessation of bone growth.

I wish to express my thanks to my colleagues, Drs. B. S. Rose and P. W. Conlon, who put their cases at my disposal and encouraged this study.

\section{References}

Ansell, B. M. (1969) Proc. roy. Soc. Med., 62, 912 (Still's disease followed into adult life).

- AND Bywaters, E. G. L. (1956) Ann. rheum. Dis., 15, 295 (Growth in Still's disease).

—_ (1959) Bull. rheum. Dis., 9, 189 (Prognosis in Still's disease).

Calabro, J. J., and Marchesano, J. M. (1967) New Engl. J. Med., 277, 696 (Current concepts: Juvenile rheumatoid arthritis).

Edström, G. (1967) Acta rheum. scand., 13, 5 (Juvenile rheumatoid arthritis: Introduction to the symposium).

DUTHIE, R. B. (1965) Personal communication.

Jacqueline, F., Boujot, A., AND CANET, L. (1961) Arthr. and Rheum., 4, 500 (Involvement of the hips in Juvenile rheumatoid arthritis).

SAIRANEN, E. (1958) Acta rheum. scand., Suppl. 2 ('On Rheumatoid Arthritis in Children').

Whillans, D., AND Fischman, A. (1958) Ann. rheum. Dis., 17, 383 (Rose-Waaler test using a rapidly prepared serum fraction). 